\title{
Basics of mechanical ventilation for non-anaesthetists. Part 1: Theoretical aspects
}

\begin{abstract}
The expanding number of chronic respiratory diseases and the new COVID-19 outbreak create an increasing demand for mechanical ventilation (MV). As MV is no longer limited to intensive care units (ICU) and operating rooms (OR), more clinicians should acquaint themselves with the principles of mechanical ventilation. To fully acknowledge contemporary concepts of MV, it is crucial to understand the elemental physiology and respiratory machine nuances. This paper addresses the latter issues and provides insight into ventilation modes and essential monitoring of MV.
\end{abstract}

Key words: mechanical ventilation, acute respiratory distress syndrome, mechanical ventilators, respiratory physiology, mechanical ventilation modes

Adv Respir Med. 2020; 88: 424-432

\section{Introduction}

The epidemic of childhood paralysis (poliomyelitis) in 1952 in Denmark was a breakthrough in the development of modern mechanical ventilation. Then, for the first time on a large scale, positive pressure ventilation was applied. Self-inflating bags (so-called Ambu) were used, thanks to which, the given respiratory volume was pressed into the lungs, significantly reducing the mortality of patients with severe acute respiratory failure. Although the procedure was poorly standardised and fraught with the risk of complications, the event itself revolutionised the approach to mechanical ventilation. Polish data demonstrate that more than $70 \%$ of patients hospitalised in intensive care units (ICU) require treatment with a ventilator [1]. All patients in operating theatres, undergoing general anaesthesia, also require mechanical ventilation with a ventilator built into the anaesthesia apparatus. In addition to applications within the ICU and operating theatre, there is an increasing incidence of diseases requiring periodic respiratotherapy at home, i.e., chronic obstructive pulmonary disease (COPD) and obesity hypoventilation syndrome.
Furthermore, due to the current COVID-19 pandemic, the number of people requiring mechanical ventilation is growing. The latest data regarding SARS-CoV-2 indicate that mechanical ventilation must be implemented in $56 \%$ of patients admitted to ICU [2], and a rapidly growing population of patients requiring ventilation may exceed the number of available intensive care facilities. Accordingly, basic knowledge about the ventilators and the rules for their operation should be propagated (Table 1).

\section{Physiology and physics of breathing}

The human respiratory system is designed to increase the dimensions of the chest and create negative pressure, which allows suction of the air through the mouth and nose (according to Boyle-Mariotte's law [4], with the increase in gas volume, its pressure decreases). Gas, therefore, travels through the bronchial tree and reaches the alveoli, levelling the pressure gradient between the lungs and the atmosphere. The sucked air takes part in gas exchange and then the chest returns to its primary state resulting in exhalation due to reversal of pressure - collapsing chest

Address for correspondence: Łukasz J Krzych, Chair and Department of Anaesthesiology and Intensive Care, Medical University of Silesia in Katowice, Poland; e-mail: I.krzych@wp.pl DOI: $10.5603 / A R M . a 2020.0143$

Received: 27.04.2020

Copyright (C) 2020 PTChP

ISSN 2451-4934 
Table 1. Basic, non-surgical indications for mechanical ventilation [3]

Protection from the respiratory tract obstruction in patients with reduced level of consciousness (Glasgow coma scale $\leq 8 \mathrm{pkt}$ )

Hypercapnic $\left(\mathrm{PaCO}_{2}>60 \mathrm{~mm} \mathrm{Hg}\right)$ respiratory failure due to hypoventilation (respiratory muscles/respiratory tract / thoracic wall disorders)

Hypoxemic respiratory failure $-\mathrm{SaO}_{2}<90 \%$ during passive oxygen therapy, or $\mathrm{PaO}_{2}<60 \mathrm{~mm} \mathrm{Hg}$

Circulatory failure in which mechanical ventilation can reduce the oxygen cost of breathing

creates a positive pressure (in relation to atmospheric pressure) that throws the volume of air out the lungs into the atmosphere.

To breathe, the lungs must overcome a certain work of breathing (WOB), which is expressed as WOB $[J]=\mathrm{V} \times \mathrm{p}$, where "V" is a volume of inhaled air, while "p" is the pressure produced (in case of physiological breath — vacuum) required to overcome resistance and perform inhalation.

The suction of air has to overcome two types of resistance. The first, representing $70 \%$ of the breathwork, is an elastic resistance (potential energy accumulated in elastic lung tissue), the second resistance, which represents about $30 \%$, is the so-called non-elastic resistance (air resistance and viscosity resistance of gases). Calculations indicate that in one minute, at rest, breathing work of about $3 \mathrm{~J}$ is performed. In incapacitated people, due to increased respiratory propulsion, energy expenditure can increase to about $15 \mathrm{~J} / \mathrm{min}$ [5]. Then the energy expenditure is already the maximum and the only way to improve the patient's condition is to use mechanical ventilation, which can reduce and even endure the need for any work by the patient.

The lungs, as well as the chest, have their compliance, which is expressed with the following formula: $\mathrm{C}\left[\mathrm{mL} / \mathrm{cmH}_{2} \mathrm{O}\right]=\mathrm{V} / \mathrm{p}$, where " $\mathrm{C}$ " is compliance, " $\mathrm{V}$ " is the volume of air and " $\mathrm{P}$ " is intra-alveolar pressure. Compliance shows the ability of the lungs to increase volume without a significant rise in alveolar pressure. The higher the " $C$ ", the greater the lung's ability to maintain low pressure [6]. Compliance is important since an increase in pulmonary pressure can lead to "barotrauma" (pressure lung damage). All ventilators have respiratory pressure sensors and, in case there is an unwanted increase, overpressure valves open, releasing excessive gas.

The sucked gas, flowing through the respiratory tract, encounters resistance from the walls of the trachea, larynx and bronchi. This resistance is expressed by the following formula:

$\mathrm{R}\left[\mathrm{cmH}_{2} \mathrm{O} / \mathrm{L} / \mathrm{s}\right]=8 \mathrm{hl} / \Delta \mathrm{pr}^{4}$, where "h" means the viscosity of the gas, "l" - pipe length, "r" - radius of the tube and " $\Delta \mathrm{p}$ " is a pressure gradient at the beginning and end of the tube (respiratory system). Resistance means the pressure gradient in the respiratory system that must be applied to trigger a specific airflow. The essential element of this formula is the radius of the respiratory tract - the smaller it is, the greater the resistance. In case of diseases that reduce the diameter of the respiratory tract (i.e., too narrow intubation tube, a tube filled with mucus), the ventilator must use higher pressures to provide the patient with adequate respiratory volume within the correct time. It should also be remembered that the mere use of an intubation tube (which has a lower diameter than physiological trachea) and the inspiratory arm of the ventilator (prolongation of the physiological respiratory tract) increases resistance in the ventilation system [6].

One of the most important parameters for ventilation is the pressure measured in the respiratory system at the end of the expiration. This is a crucial parameter for the effectiveness of mechanical ventilation. Often, as a result of a disease, an increase in the elastic forces of the lungs occurs and the alveoli collapse, worsening the efficacy of gas exchange. An example of such a disorder is acute respiratory distress syndrome (ARDS) or hyaline membrane disease in newborns, both associated with a deficiency of surfactant. Surfactant reduces the surface tension of the alveoli [6, 7], which is expressed by Laplace's law: $\sigma[\mathrm{dyn} / \mathrm{cm}]=\mathrm{p} \times \mathrm{r} / 2$, where " $\sigma$ " is surface tension, "p" is the pressure that pushes the walls of the alveoli, "r" - the radius of the alveoli. As a result of surfactant deficiency, surface tension increases, thus alveoli collapse. Artificial increase in the positive end-expiratory pressure (PEEP) applied by the ventilator allows to oppose the force collapsing the alveoli and thus maintaining the patency of the airways.

During mechanical ventilation, the anatomical dead space must be taken into consideration. Physiologically, conductive parts of the respiratory system (larynx, trachea and bronchi) do not participate in gas exchange. Hence a certain volume of sucked air remains unused. If a person inhales $500 \mathrm{~mL}$ of air, approximately $150 \mathrm{~mL}$ remains in the dead space [6]. A ventilator's pipe system enlarges this space, which is especially important during exhalation - if there is a significant expansion of a dead space, there may 
be a situation in which a part of exhaled air will remain in artificial airways and the next breath will cause the remaining volume to be sucked again (to understand this fact, it may be worth imagining breathing underwater with excessively long tube). It is particularly important and poses a critical danger in ventilation of newborns, where the respiratory volumes are minimal. It should be remembered that anatomical respiratory tract and respiratory system of the ventilator, constituting a dead space, have compliance as well. This means that during ventilation with positive pressures, the respiratory tract expands, and therefore, the dead space increases. If we assume that the compliance of the dead space is $2 \mathrm{~mL} / 1 \mathrm{cmH}_{2} \mathrm{O}$, then with a positive pressure of $25 \mathrm{cmH}_{2} \mathrm{O}$, the dead space will increase by as much as $50 \mathrm{~mL}$ [8].

Monitoring ventilation is not an easy task. One of its elements is the evaluation of the pressure-time curve (Figure 1A). Its analysis allows to understand how pressure behaves in the patient's respiratory system. The following figure illustrates a situation in which the ventilator is intended to push the given volume into the patient's respiratory system.

Point (1) illustrates the start of the inspiratory phase by the ventilator. A positive pressure is produced, which from point (1) to (2) takes on the curve a near-vertical form (rapidly increasing pressure), overcoming the resistance of the system. This is also due to the fact that the compliance of the ventilation tube (orotracheal, nasotracheal, tracheotomy) and the pipe system is very low. Then, the pressure increases with slightly less dynamics, which is due to the patient's respiratory tract compliance. It should be remembered that in people with increased respiratory resistance, e.g. in an asthma attack, increasing pressure will show higher values. At point (3), the peak pressure of the inhaled air is achieved (PIP, peak inspiratory pressure). Then the ventilator interrupts inhalation (but does not start expiration yet). The previously produced pressure suddenly drops (4), which is directly due to the compliance of the patient's lungs. Then this pressure slightly decreases to a value known as plateau pressure. If the patient's lungs had lower compliance than healthy ones, plateau pressure would show higher values. After that, the ventilator starts expiratory phase, leading to a drop in pressure to a point (6), where it is equated with the final exhaust pressure, which usually takes a positive value (PEEP), provided by a ventilator [9].

\section{Construction of the ventilation system}

In addition to the ventilator and electricity, the ventilation system includes a source of compressed gases, an inhaled arm, the patient's respiratory system and an expiratory arm (Figure 2).

\section{Gas source for ventilator}

Today's hospitals are equipped with central compressed gas source systems. They are the driving force behind artificial ventilation pneumatics. The ventilator is connected to two such tanks, one with oxygen (Figure 2 A1) and the other with air (Figure 2 A2). The pressure in the tanks is about 5 bar $\left(5098 \mathrm{cmH}_{2} \mathrm{O}\right)$ [10]. This is very high pressure for the respiratory system, so the ventilator is also responsible for reducing pressure to tolerated values. Gases should be dry, free of water vapor. The connection to the gas tank, nevertheless, contains water traps to prevent water from entering the ventilatory system.

\section{Ventilator}

There are several types of ventilators. However, due to the capacity restrictions of the manuscript, the most commonly used type of respirator (pneumatic-electric) will be described [10]. Due to the additional structure variability of the device depending on the manufacturer, for easier understanding of the article, the Puritan-Bennet 840 ventilator ${ }^{\circledR}$ (used in our centre) was described as an example. Regardless of the ventilator model, the physical aspects of ventilation remain the same. As mentioned earlier, the gases from the tank must be subjected to pressure reduction. For this purpose, the ventilator has pressure regulators (Figure 2B) that precisely lower the pressure of gases to the optimal values for the functioning of the machine. Then the gases flow through the so-called flowmeters (Figure 2C). These are the devices operating on the principle of a pneumotachograph and use Hagen-Poiseuille law: $\mathrm{V}[\mathrm{l} / \mathrm{s}]=\Delta \mathrm{pr}^{4} / 8 \mathrm{hl}$, where "V" means flow, " $\Delta \mathrm{p}$ " - pressure gradient at the beginning and end of the tube (system), "r" is the radius of the tube, "h" - the viscosity of the flowing liquid (gas) and "l" is the length of the tube.

The gas flows through the resistance pipes and creates the pressure gradient, which is measured by the pressure sensor. According to the formula above, a higher pressure gradient indicates a higher flow. Information from the pressure sensor, obtained by analysing the pressure force on the sensor membrane, is transmitted to the ventilator processor. Then, the gas goes to the so-called pro- 
A

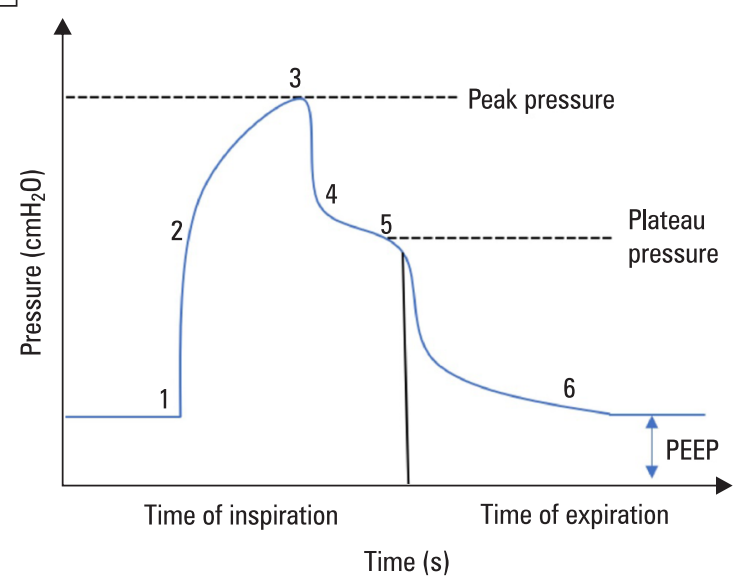

C

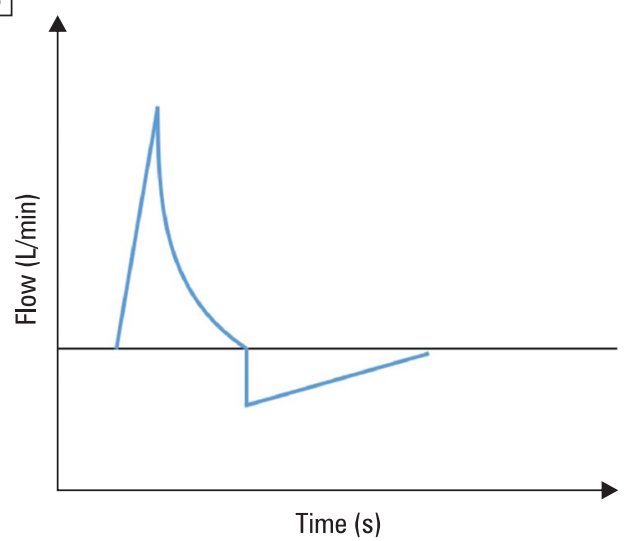

$\mathbf{E}$

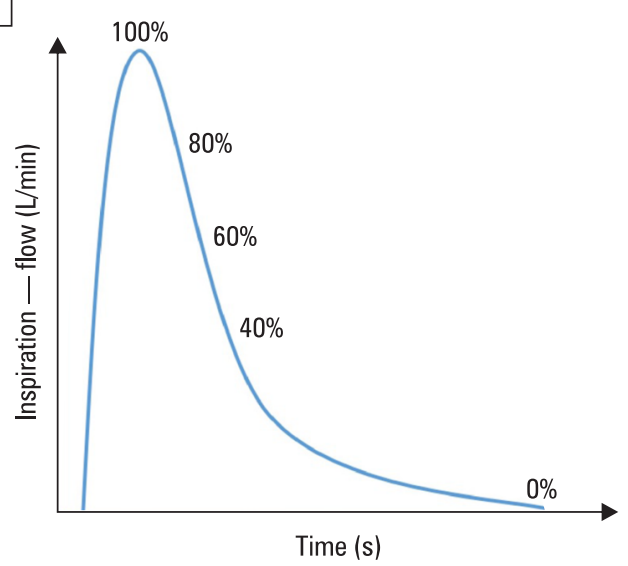

B

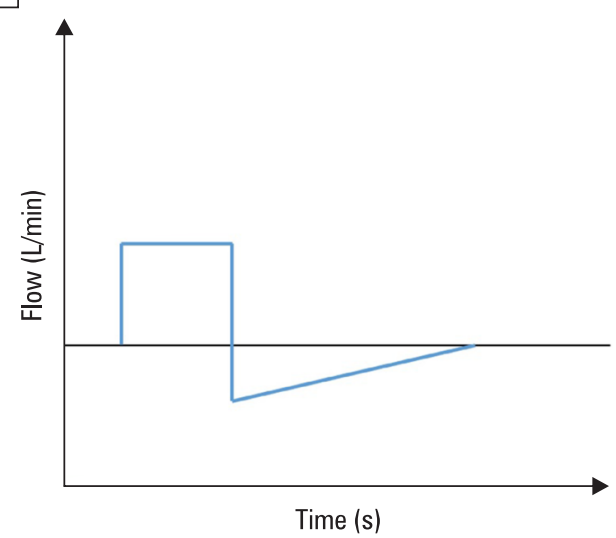

D

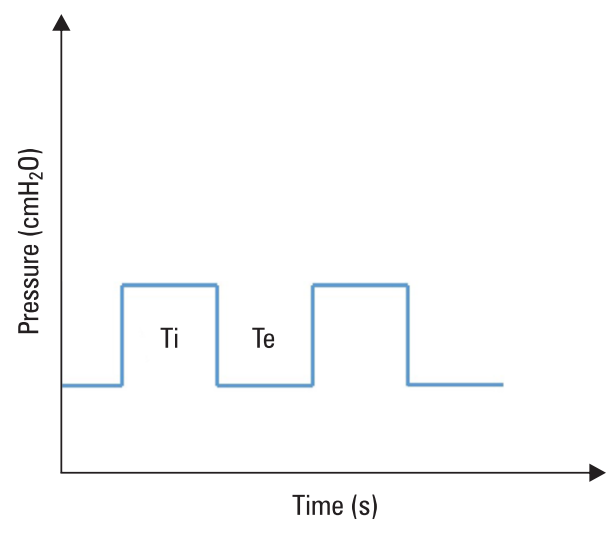

Figure 1. A. Pressure-time curve in volume-controlled ventilation (based on [9]); B. Gas flow curve during volume-controlled ventilation (VCV); C. Gas flow curve during pressure controlled ventilation (PCV); D. Changes in the breathing phase. $\mathrm{Ti}$ - inhalation time, Te - exhalation time; E. Inspiratory flow curve. See text for details

portional solenoid valve (Figure 2D), controlled by a ventilator processor. It can modify the volume flowing through the ventilator in a very accurate way. This structure is thus responsible for creating an adequate volume of gas to be found in the patient's respiratory system. The ventilator also has a safety overpressure valve (Figure 2E). In the event of an unwanted increase in the gas pressure in the ventilator system (usually a limit pressure of $100-120 \mathrm{cmH}_{2} \mathrm{O}$ ), the valve (spring or electrically controlled) is unlocked and the gas from the ventilator is released. It is worth mentioning that this structure also provides the patient with access to atmospheric air, in case of a sudden loss of air in 


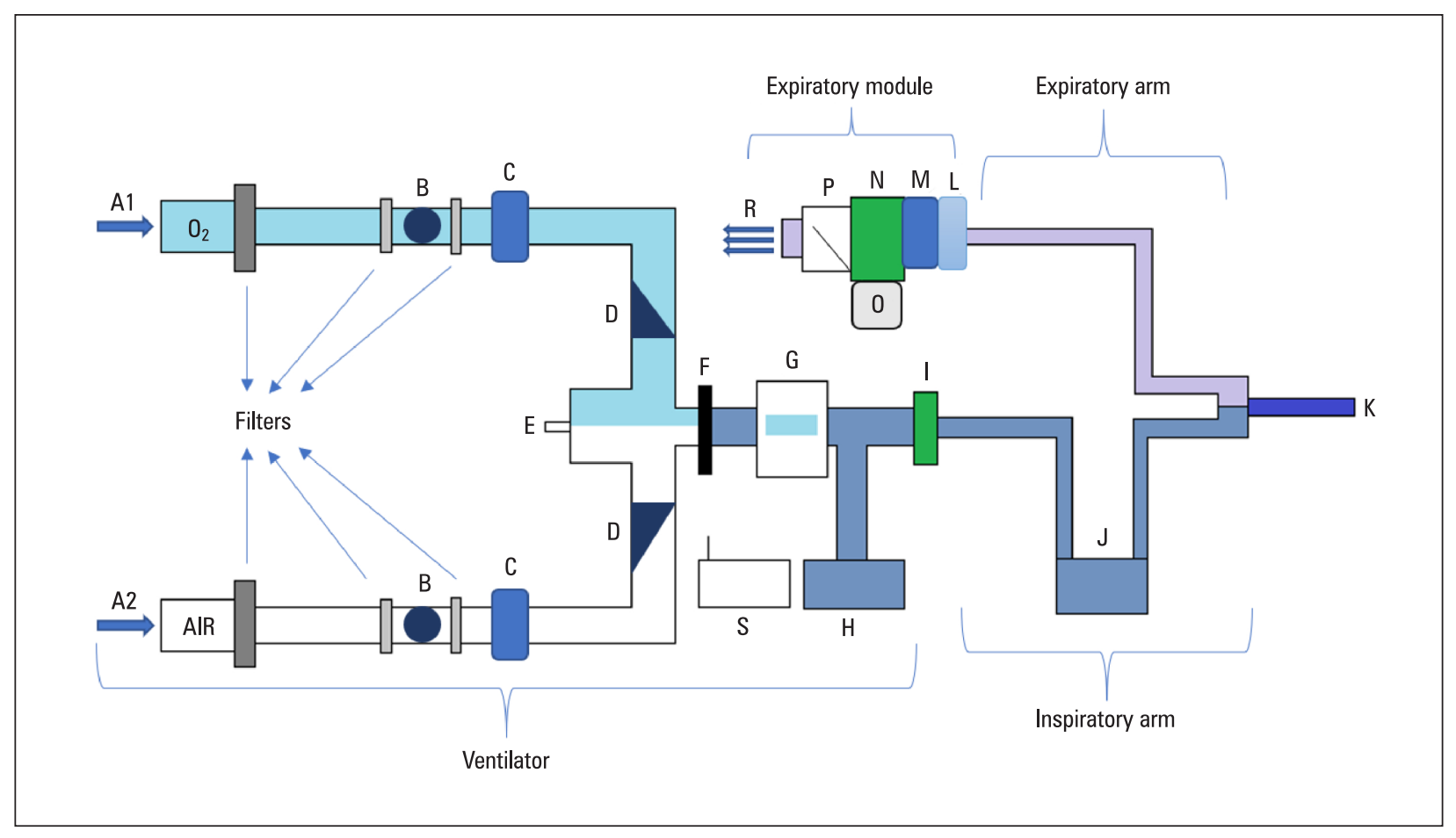

Figure 2. Ventilation system (based on [11])

the system (the patient can then take air from the environment with his own breath). Then, the oxygen and air merge in the system. Then the ventilator must measure the oxygen concentration in the inhaled mixture, which is done with a galvanic cell (Figure 2G). As a result of the chemical reaction $\left(\mathrm{O}_{2}+\mathrm{KOH}\right)$, a voltage correlated with oxygen concentration is formed. Depending on the patient's demand, the oxygen concentration in the mixture can range from $21 \%$ to $100 \%$. A one-way valve (Figure 2F) is responsible for the direct supply of gases to the inspiratory arm. During inspiration, it opens, releasing a pre-prepared mixture. The pressure of such a compound is measured again by the pressure sensor (Figure $2 \mathrm{H}$ ). The next, an essential and integral part of the ventilator is the atmospheric pressure sensor (Figure 2R), as all pressures recorded by the ventilator refer to the atmospheric pressure value. Therefore, if the recorded pressure in the respiratory system was $10 \mathrm{~mm}$ $\mathrm{Hg}$, it was in fact $770 \mathrm{~mm} \mathrm{Hg}(10+760 \mathrm{~mm} \mathrm{Hg})$. If for some reason, atmospheric pressure had fallen and the ventilator did not make a correction, then the applied pressures in the patient's respiratory system would be significantly higher, as it would still refer to the original atmospheric pressure. The problem of frequent and large changes in atmospheric pressures occurs, for example, in case of air transport of an intubated and mechanically ventilated patient [10-11].

\section{Inspiratory arm}

The inspiratory arm brings the air to the patient's respiratory system. There must be a filter (Figure 2I) between the ventilator and the arm. Although the gases delivered to the patient are free of microbes, if the aforementioned overpressure valve is used, there may be airflow in the opposite direction - from the patient to the ventilator, creating a threat of microbial contamination. Gases from hospital gas tanks are dry and have a lower temperature than body temperature. One of the functions of the human respiratory tract (especially the nose), is moisturising and warming the inhaled air. In ventilated patients, due to the use of intubation tubes or tracheostomy tubes, this element of the respiratory tract is omitted and unchanged air enters the lungs. The inhaled arm must, therefore, take over the function of warming and hydration. Air passes through the water chamber and heater (Figure 2J) (or heat and moisture exchanger, HME), where it gets saturated with water vapour. The air reaching the lungs should be moistened at a rate of 33 to $41 \mathrm{mg} / \mathrm{L}$ with a temperature of $34-41^{\circ} \mathrm{C}$. Relative humidity should be $100 \%$.

The warmed and moistened gas travels along with the system through the inhaled arm. Therefore, if it is not actively heated, the gas temperature will decrease in it, which means that the absolute humidity of the air will drop and steam 
will begin to condense on the walls of the pipe. This carries the risk of increased resistance in the system. This is prevented by water traps, thanks to which the water flows into the reservoir, according to the force of gravity. Instead of water traps, active heating of the inhaled arm can be used. As a result, the moisture gas temperature will not drop, so the absolute humidity will remain identical to that created in the humidifier (a similar solution must be introduced in the expiratory arm). After passing through the inspiratory arm, the air flows into the intubation tube (Figure $2 \mathrm{~K})$ and then into the patient's lungs [8, 10-12].

\section{Expiratory arm}

After inhalation and gas exchange, exhalation time comes. The inspiratory valve closes, the expiratory valve opens and the breathing mixture flows through the expiratory arm. The air then enters the expiratory module, where it passes through the flowmeter (Figure 2L), the pressure sensor (Figure 2M), the filter (Figure $2 \mathrm{~N}$ ), the water trap (Figure 2O) and the expiratory valve (Figure 2P). The expiratory valve not only opens and closes to allow exhalation, but is also able to produce PEEP: thanks to the possibility of controlled, partial opening or closing, it increases expiratory resistance in the patient's respiratory system, creating the positive pressure at the end of the expiration (PEEP), and thus increasing the volume and pressure of gas in the alveoli. The gas mixture then leaves the ventilation system, getting into ambient air (Figure 2R) [8, 10, 11].

\section{Basic variables and ventilation modes}

Ventilation mode is the result of the variables described below, which together provide the most effective breathing for the patient. Unfortunately, to this day, there are no fully unified and standardised rules for naming the modes and as a rule, every company producing ventilators introduces its own nomenclature, which can be confusing for the novice user.

\section{Control}

"Control" refers to the way gas is delivered to the patient's lungs. There are two basic types of controls. The first is the volume-controlled ventilation (VCV) (Figure 1B) - a ventilator presses a fixed volume of air, regardless of the resulting pressure in the respiratory system (irrespective of compliance and resistance). The rigidly accepted respiratory volume carries a higher risk of lung damage (if the pressures in the patient's lungs were too high). The second way of control is pressure-controlled ventilation (PCV). Here, inverse to the volume-controlled, the ventilator determines the appropriate pressure to be applied in the respiratory tract during breath (Figure 1C). The volume of the pressed air will, therefore, reach the value based on the set pressure. This method allows for better cooperation between the actively breathing patient and the ventilator (the machine does not affect the respiratory volume directly). This means that the patient can partially control the inspiratory volume with his own efforts. Pressure control also compensates gas leakage in the ventilation system. If the intubation tube cuff is leaking, there is a risk of gas escaping from the lungs. In PCV, the ventilator will pursue adequate pressure in the respiratory system. In volume control, such leak carries the risk of an unnoticed decrease in ventilation [12]. The question which of the aforementioned types of control brings a better result of treatment, for now, remains unanswered. The results of a randomised study published by Chacko et al. in 2015 suggest that there is no significant difference in reducing patient mortality between described ventilation methods [14].

\section{Breathing sequence}

The breathing sequence is used to determine how the frequency of breathing is carried out. There are three basic types of breathing sequence: CMV (continuous mandatory ventilation), in which the doctor rigidly sets the strict number of breaths to be provided by the ventilator. This sequence does not give the patient the opportunity to initiate his own inspiration; IMV (intermittent mandatory ventilation), in which the doctor determines the frequency of breaths, however, the patient can initiate his own breath between mandatory breaths, which is recognised by the ventilator and assisted; and CSV (continuous spontaneous ventilation), in which every breath is initiated by the patient, while the ventilator acts only as a breath-support [15].

\section{Control type}

The type of control determines the target of the ventilation. If the VCV is carried out, then the goal may be a ventilation volume equal to $6 \mathrm{~mL} / \mathrm{kg}$ of ideal body weight (IBW). This target is known as the set point. The ventilator will adjust the appropriate pressures in the system so that the volume set by the doctor is applied. There is also the auto set-point in which the ventilator decides what target to achieve at the 
moment - e.g., in the volume-assured pressure support mode, ventilation starts with pressure control, and then completes the patient's inspiration by volume control to maintain a specific volumetric target of ventilation. In the Servo type, the ventilator recognises the patient's respiratory work and, depending on it, adjusts the degree of pressure or volume support to it. An example of such solution is the PAV mode (proportional assist ventilation) [16].

There are two additional types of controls that relate not only to a single inspiration, as the ones described above (PCV, VCV), but to the analysis of the previous breaths and then, subsequently, modify the parameters to the changing respiratory conditions. Thus, there is an adaptive type that analyses the resulting respiratory volume in the interval between breaths and then modifies the pressures so that at the next breath, it is as close as possible to the original assumption. The type of optimisation assumes the automatic adaptation of set-points to optimise respiratory work of the patient (WOB). Such solutions are used in adaptive support ventilation (ASV) mode [15].

\section{Inhalation trigger}

Pushing the air into the patient's lungs can be initiated in different ways (so-called trigger). The first, the easiest one is time triggering. This means that the ventilator initiates the breath itself in a certain time interval. If we set the breathing rate for 15 times per minute, that means the inspiration will be triggered by a ventilator every 4 seconds, with a given inspiration-to-expiration ratio. It is used in CMV mode. The second type is the pressure trigger - the patient, wanting to inhale the air, provokes a drop in pressure in the ventilation system. The ventilator, thanks to the presence of pressure sensors, recognises this phenomenon as an impulse to initiate a breath. While setting the pressure threshold to trigger inhalation, it should be remembered that it is not too low because of a risk of spontaneous, unintentional inducing the ventilator. The next, third way of triggering, is the flow trigger. It is the most popular type in spontaneous breathing modes. The ventilator recognises the moment to start the breath by the patient's attempt to inhale, but the sensors in this method are flowmeters, which identify the airflow [13].

\section{Change of the respiratory phase (Figure 1D)}

There are three most common methods for changing the phase of breathing. Time change means that a clinician can directly set the time needed for inspiration - for e.g., 3 seconds. After this time, the ventilator will automatically switch to an expiration mode. It is also possible to set the time ratio of inhalation to exhalation (I:E). If I:E is e.g., change 1:2, it means that for 20 breaths/min, breathing cycle would last 3 seconds $(60 / 20)$ and the time spent on inhalation would be 1 second and 2 seconds for exhalation (thus, 1:2 ratio). Usually, I:E ratio of 1:2 is set [18]. However, it should be remembered that in patients with hyperinflation of the lungs (e.g. in patients with emphysema), the expiration period must be extended to remove the residual air more effectively [19]. On the other hand, with the increase in the number of breaths, usually above 20/minute, the duration of the expiration should be reduced to allow effective inspiration - usually I:E 1:1.5 or 1:1. Another type of phase change is flow change, which is usually used in pressure control. The ventilator changes the inspiration phase to expiration when the inhalation flow drops to a certain percentage value (Figure 1E) - usually 25\% of maximal flow. The third way of changing the breathing cycle is the pressure phase, commonly used in volume control. When the maximum permitted pressure in the respiratory system is reached, the inhalation phase changes to expiration. This protects the patient's lungs from barotrauma [13].

The synthesis of these issues is presented in Table 2.

One of the most common modes used is the SIMV + PS - mandatory ventilation using volume control in a patient who does not initiate the breath himself. However, if the patient initiates his own breaths, the mode switches to the socalled Pressure Support (PS), in which breathing is carried out with pressure support. In this way, the patient is protected from central apnoea, but is also able to interfere in his breathing cycle, so the risk of dis-synchrony of the patient-ventilator is reduced [20]. A simple algorithm showing the selection of ventilation mode is shown in Figure 3.

\section{Conclusions}

At the root of mechanical ventilation are physical issues, without which it is impossible to understand the specifics of the work of the ventilator. Familiarisation with these considerations is the gateway to understanding the concurrent concepts of ventilation. Respiratotherapy includes the integration of many components, the most important of which is the patient. It is necessary to be aware of the limitations and dangers 
Table 2. Examples of popular mechanical ventilation modes [14, self-modified]

\begin{tabular}{|c|c|c|c|c|c|c|c|c|}
\hline \multirow[b]{2}{*}{ Mode } & \multirow[b]{2}{*}{ Control } & \multicolumn{4}{|c|}{ Mandatory breaths } & \multicolumn{3}{|c|}{ Spontaneous breaths } \\
\hline & & $\begin{array}{l}\text { Breathing } \\
\text { sequence }\end{array}$ & Control type & Triggering & $\begin{array}{l}\text { Phase } \\
\text { change }\end{array}$ & Control type & Triggering & $\begin{array}{l}\text { Phase } \\
\text { change }\end{array}$ \\
\hline VCV & Volume & CMV & Set-point & Time & Time & - & - & - \\
\hline SIMV & Volume & IMV & Set-point & Time/flow & Time & Set-point & Pressure & Pressure \\
\hline PS & Pressure & CSV & - & - & - & Set-point & Pressure & Pressure \\
\hline CPAP & Pressure & CSV & - & - & - & Set-point & Pressure & Pressure \\
\hline PAV & Pressure & cSV & - & - & - & Optimazation & Flow & Flow \\
\hline
\end{tabular}

CMV — continuous mandatory ventilation; CPAP — continuous positive airway pressure; CSV — continuous spontaneous ventilation; IMV — intermittent mechanica ventilation; PS — pressure support; PAV — proportional assisted ventilation; SIMV — synchronized intermittent mandatory ventilation; VCV — volume controlled ventilation;

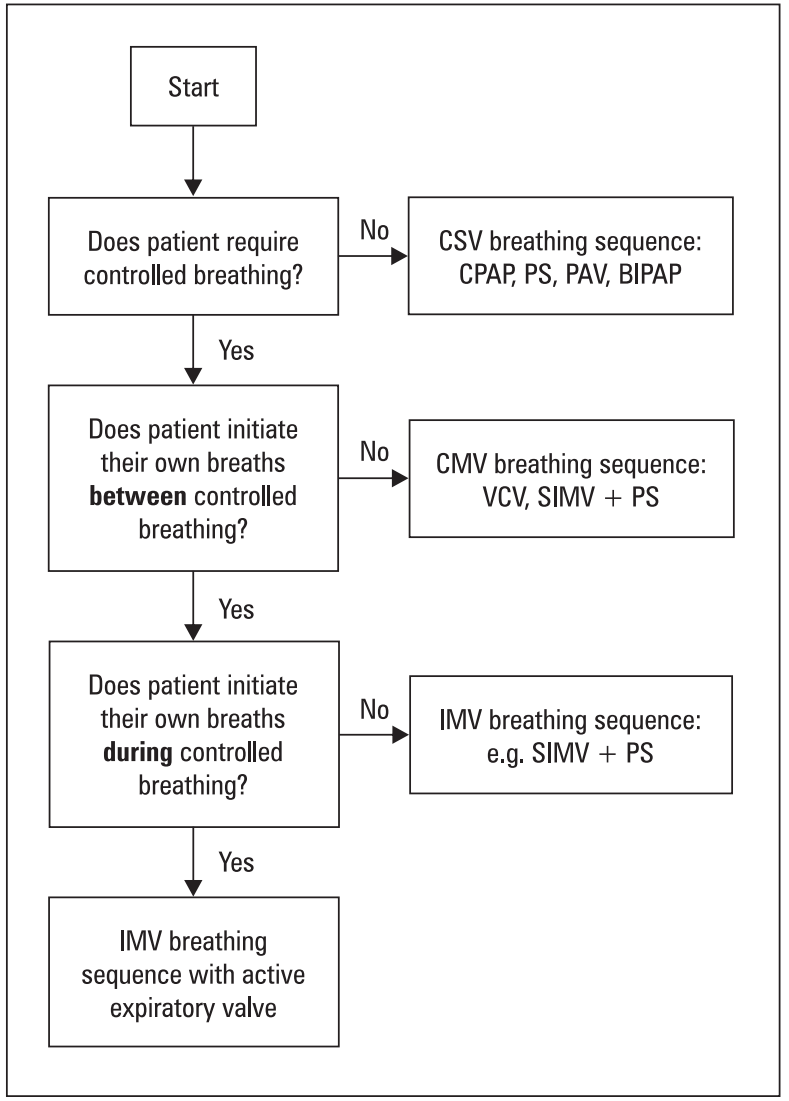

Figure 3. Algorithm of basic selection of ventilation mode [14, self-modification]. BIPAP — biphasic positive airway pressure; CMV - controlled mechanical ventilation; CPAP — continuous positive airway pressure; IMV — intermittent mechanical ventilation; PAV — proportional assist ventilation; PS — pressure support; SIMV + PS - synchronized intermittent mechanical ventilation + pressure support; VCV — volume controlled ventilation

arising from the use of positive pressures, which, despite being at odds with the physiological way of breathing, are now the most common method of sustaining human breathing.

\section{Conflict of interest}

None declared.

\section{References:}

1. Kübler A, Maciejewski D, Adamik B, et al. Mechanical ventilation in ICUs in Poland: a multi-center point-prevalence study. Med Sci Monit. 2013; 19: 424-429, doi: 10.12659/ MSM.883930, indexed in Pubmed: 23727991.

2. Yang X, Yu Y, Xu J, et al. Clinical course and outcomes of critically ill patients with SARS-CoV-2 pneumonia in Wuhan, China: a single-centered, retrospective, observational study. The Lancet Respiratory Medicine. 2020; 8(5): 475-481, doi: 10.1016/s2213-2600(20)30079-5.

3. Pham T, Brochard LJ, Slutsky AS. Mechanical ventilation: state of the art. Mayo Clin Proc. 2017; 92(9): 1382-1400, doi: 10.1016/j.mayocp.2017.05.004, indexed in Pubmed: 28870355.

4. Pilawski A, Puchalik M. Strukturalne właściwości materii, Podstawy biofizyki: podręcznik dla studentów medycyny. Pilawski A (ed.). PZWL, Warszawa 1985: 69-95.

5. Pilawski A. Biofizyka układu oddechowego, Podstawy biofizyki: podręcznik dla studentów medycyny. Pilawski A (ed.). PZWL, Warszawa 1985: 311-323.

6. Gutkowski P, Konturek S. Fizjologia oddychania, fizjologia człowieka. Podręcznik dla studentów medycyny. Konturek S (ed.). Elsevier Urban \& Partner, Wrocław 2013: 235-303.

7. Halliday HL. The fascinating story of surfactant. J Paediatr Child Health. 2017; 53(4): 327-332, doi: 10.1111/ipc.13500, indexed in Pubmed: 28271629.

8. Yuan Lei. Budowa systemu wentylacyjnego, Respiratory. Przewodnik Kliniczny. Łazowski T (ed.). Makmed, Lublin: 2018, 65-97.

9. Rittner F. Curves and loops in mechanical vVentilation. Drager Technology for Life Dragerwerk AG and Co KGaA, Lubeck, 2015: 4-60.

10. Traczyk J. Budowa respiratora, wentylacja mechaniczna - teoria i praktyka. Maciejewski D, Wojnar-Gruszka K (ed.). $\alpha$-medica press, Bielsko-Biała 2016: 61-117.

11. Service Manual Puritan Bennet 840 Ventilator System. Available online: www.medtronic.com/content/dam/covidien/library/us/en/product/acute-care-ventilation/PB840_Technical_ Reference_Manual_EN_10067720D00.pdf. [Last acccessed at: 10.02.2020].

12. Yuan Lei. Nawilżanie, nebulizacja i filtrowanie gazów. Respiratory. Przewodnik Kliniczny. Łazowski T (ed.). Makmed, Lublin 2018: 101-133.

13. Yuan Lei. Podstawowe zmienne i typy oddechu. Respiratory. Przewodnik Kliniczny. Łazowski T (ed.). Makmed, Lublin 2018: 137-161. 
14. Chacko B, Peter J, Tharyan P, et al. Pressure-controlled versus volume-controlled ventilation for acute respiratory failure due to acute lung injury (ALI) or acute respiratory distress syndrome (ARDS). Cochrane Database of Systematic Reviews. 2015, doi: 10.1002/14651858.cd008807.pub2.

15. Chatburn RL. Classification of ventilator modes: update and proposal for implementation. Respir Care. 2007; 52: 301-323.

16. Younes M. Proportional assist ventilation, a new approach to ventilatory support: theory. American Review of Respiratory Disease. 1992; 145(1): 114-120, doi: 10.1164/ajrccm/145.1.114.

17. Yuan Lei. Podstawowe zmienne i typy oddechu. Respiratory. Przewodnik Kliniczny. Łazowski T (ed.). Makmed, Lublin 2018: 137-161.
18. Park JHa, Lee JS, Lee JH, et al. Effect of the prolonged inspiratory to expiratory ratio on oxygenation and respiratory mechanics during surgical procedures. Medicine (Baltimore). 2016 95(13): e3269, doi: 10.1097/MD.0000000000003269, indexed in Pubmed: 27043700.

19. Reddy RM, Guntupalli KK. Review of ventilatory techniques to optimize mechanical ventilation in acute exacerbation of chronic obstructive pulmonary disease. Int J Chron Obstruct Pulmon Dis. 2007; 2: 441-452.

20. Maciejewski D. Podstawowe tryby wentylacji mechanicznej Wentylacja mechaniczna - teoria i praktyka. Maciejewski D, Wojnar-Gruszka K (ed.). $\alpha$-medica press, Bielsko-Biała 2016, 154-193. 